\title{
Article \\ Efficient, Sustainable, and Multifunctional Carbon Offsetting to Boost Forest Management: A Comparative Case Study
}

\author{
Timothée Fouqueray ${ }^{1, * \mathbb{C}}$, Lucile Génin ${ }^{1}$, Michel Trommetter ${ }^{2}$ and Nathalie Frascaria-Lacoste ${ }^{1}$ \\ 1 Ecologie Systématique Evolution, CNRS, AgroParisTech, Université Paris-Saclay, 91405 Orsay, France; \\ lucile.genin@sciencespo.fr (L.G.); nathalie.frascaria@universite-paris-saclay.fr (N.F.-L.) \\ 2 GAEL, Grenoble INP, CNRS, INRAE, Université Grenoble Alpes, 38000 Grenoble, France; \\ michel.trommetter@inrae.fr \\ * Correspondence: timothee.fouqueray@uqo.ca
}

Citation: Fouqueray, T.; Génin, L.; Trommetter, M.; Frascaria-Lacoste, N. Efficient, Sustainable, and Multifunctional Carbon Offsetting to Boost Forest Management: A Comparative Case Study. Forests 2021, 12, 386. https://doi.org/10.3390/ f12040386

Academic Editor: Jessica Leahy

Received: 22 February 2021

Accepted: 22 March 2021

Published: 24 March 2021

Publisher's Note: MDPI stays neutral with regard to jurisdictional claims in published maps and institutional affiliations.

Copyright: (c) 2021 by the authors. Licensee MDPI, Basel, Switzerland. This article is an open access article distributed under the terms and conditions of the Creative Commons Attribution (CC BY) license (https:// creativecommons.org/licenses/by/ $4.0 /)$.

\begin{abstract}
Research highlights: Funding forest management with subsidies from carbon offsetters is a well-documented mechanism in tropical regions. This article provides complementary insights into the use of voluntary offset contracts in temperate forests. Background and objectives: The mitigation of greenhouse emissions has become a major global issue, leading to changes in forest management to increase the capacity of forests to store carbon. This can lead to conflicts of use with other forest ecosystem services such as timber production or biodiversity conservation. Our main goal is to describe collective actions to fund carbon-oriented forestry with subsidies from carbon offsetters and to analyze how their governance and functioning prevent conflicts pertaining to multi-functionality. Materials and methods: We assembled an interdisciplinary research team comprising two ecologists, a social scientist, and an economist. Drawing on a conceptual framework of ecosystem services, social interdependencies, and collective action, we based our qualitative analysis on semi-structured interviews from two French case studies. Results: Carbon-oriented intermediary forest organizations offer offset contracts to private firms and public bodies. Communication is geared toward the mitigation outcomes of the contracts as well as their beneficial side effects in providing the ecosystem services of interest to the offsetters. Subsidies then act as a financial lever to fund carbon-oriented forestry operations. Scientific committees and reporting methodologies serve as environmental, social, and economic safeguards. Conclusions: These new intermediary forest organizations use efficient forest operations and evaluation methodologies to improve forest carbon storage. Their main innovation lies in their collective governance rooted in regional forest social-ecological systems. Their consideration of multi-functionality and socioeconomic issues can be seen as an obstacle to rapid development, but they ensure sustainability and avoid conflicts between producers and beneficiaries of forest ecosystem services. Attention must be paid to interactions with broader spatial and temporal carbon policies.
\end{abstract}

Keywords: forest management; multifunctionality; carbon offset; collective action; conflict avoidance; mitigation; payment for ecosystem services; social-ecological; France

\section{Introduction}

The claim that forests and foresters have witnessed significant evolutions in the last few decades is an understatement. Along with social and technical developments, it is now routine to point to global changes as drivers of the spatiotemporal trajectories of forest socioecosystems (FSES) [1]. Among the most pressing global issues (with land degradation), climate change has buoyed considerable research efforts in the forest sciences $[2,3]$.

While undeniable research progress has been made for the mitigation of and adaptation to climate change, the indirect consequences of mitigation and adaptation actions on FSES remain underexplored. To cite only mitigation, a sizeable body of literature explores the direct influence of forest management on above- and below-ground carbon 
storage [4]. However, mitigation is rarely tackled from the perspective of its social or economic consequences (e.g., [5])—with the notable exceptions of investigations into the Reducing Emissions from Deforestation and Forest Degradation (REDD+) program [6] and in some European case studies $[7,8]$.

Although it makes sense to monitor how carbon-oriented operations directly influence the role of forests as carbon sinks, the neutral, positive, or negative effects of such operations on forest multifunctionality should not be overlooked [8]. Indeed, many forest stakeholders deem the simultaneous provision of different forest ecosystem services (ES) to be critical $[9,10]$, especially the provision of timber and non-timber forest products, but also the esthetic value of managed landscapes for local communities or tourism development and the role of forest soils in water epuration, to name but a few [11].

This consideration of multifunctionality in the management of FSES also aligns with public opinion on carbon storage in forests. Particularly in Western countries, consumercitizens are putting mounting pressure on public institutions and the private sector to develop carbon offsetting schemes that do not neglect biodiversity conservation or local employment issues [12]. Turning to forest management thus gives carbon offsetters the opportunity to "kill three birds with one stone." First, forests represent an efficient and powerful lever to mitigate climate change-they already represent $14.5 \%$ of the total volume of greenhouse gas (GHG) emissions saved on voluntary markets since 2005 [13]. Second, forests benefit from a highly natural perception in civil society [14]. For companies assigning shares to sustainable forest management, this eases their response to the rising social demands for businesses to assume part of both the fight against global warming and the biodiversity crisis. Third, the frequent relocation of offset projects from tropical to temperate and boreal forests allows companies to align their environmental and social commitments [15]. Indeed, such relocations often occur in places with sound property rights, thus favoring local governance and employment, and avoiding the pitfalls of remote and potentially illegible operations, as observed with the REDD+ programs $[6,16]$.

With its forest and mitigation policies, France is a suitable illustration of this renewed interest in local forests from carbon offsetters. In terms of forests, France has Europe's fourth largest surface $\left(165,000 \mathrm{~km}^{2}\right)$, most of which is deciduous [17]. In managed forests, a tradition of multifunctionality has been legally embedded into policies, with pledges for the simultaneous provision of various ES such as timber production, recreational activities, and biodiversity conservation [18]. In terms of voluntary mitigation, France organized cross-sectional meetings in 2007 with businesses, public collectivities, and civil society stakeholders in order to promote GHG mitigation [19]. Several recommendations were later implemented in a law on corporate social and environmental responsibility (CSR), including mandatory carbon assessments $[19,20]$. Therefore, it is unsurprising that many voluntary mitigation projects have blossomed in the French forest sector since the early 2010s [21,22]. These projects are based on unprecedented partnerships linking forest owners, forestry experts, and timber industry professionals with entities seeking to compensate their GHG emissions.

The rationale of this paper is to investigate how voluntary mitigation projects boost forest management from the perspective of three essential issues, namely the efficiency, sustainability, and multifunctionality of carbon storage. Drawing deductively on a literature review on forest carbon storage [23] and inductively on our experience with forest practitioners [9], we considered that these were the three best factors predicting the success of mitigation projects. The first factor relates to the efficiency of carbon offsetting. Following Gren and Aklilu [23], we posit that any offset project must consider heterogeneity, uncertainty, additionality, and permanence issues in order to be efficient. The most important issue is proving the added value of the project (additionality), meaning that the forestry operations would not have occurred without the funding of the contract $[24,25]$. Second, the permanence risk refers to the potential carbon leakage during the duration of the offset project [15]. Third, the uncertainty of forest growth makes it difficult to predict the mitigation outcome of forestry operations [26]. Finally, the heterogeneous capacities 
of forests to store carbon complicates the calculation of the anticipated mitigation success. The second factor relates to the sustainability of carbon offsetting. To endure in the long term and recruit carbon offsetters, voluntary carbon offsetting projects must prove their added value (or "economic additionality") in comparison to baseline forest operations. The sustainability of the offset projects also implies the prevention of social conflict. Even if such conflict is not desired by FSES stakeholders, they should at least prevent any opposition. The third factor follows from the second: we assume that attention must be paid to respecting FSES multifunctionality in order to achieve carbon offsetting. Indeed, multi-objective forest operations are often inconsistent with a management geared toward only one ES, a situation commonly illustrated through the intensification of management for timber production (e.g., shortened rotation length), which can go against biodiversity conservation or the preservation of water quality among others [27-29].

Section 2 presents comparative case studies of two French organizations that bring together forest stakeholders and carbon offsetters from the private and public sectors. It also includes the conceptual framework of Barnaud et al. on ES, social interdependencies, and collective action [30] on which we based our analysis, and outlines any methodological considerations. Section 3 describes the results and depicts how the shared objective of carbon offsetting raises various organizational and governance issues. Section 4 summarizes the results of this national French study and draws conclusions at a broader scale.

\section{Materials and Methods}

\subsection{Selection of Case Studies}

The selection of case studies was guided by two steps to identify unique partnerships linking forest owners, forestry experts, and timber industry professionals (hereafter, foresters) to carbon offsetters. We restricted the area to France to allow for comparisons within the same legal and institutional framework. First, we conducted a Google survey to list French carbon mitigation projects linked to forests (Appendix A Table A1) using all possible combinations of the French keywords "forêt," "compensation carbone," and "climat" (signifying "forest," "carbon offsetting," and "climate," respectively). We crosschecked the list with a record of conferences held on forest-based carbon mitigation. The record dating back to 2016 was established using newsletters from forestry or environmental websites (https:/ / www.actu-environnement.com, https:/ / www.fransylva.fr (accessed on 5 October 2018), https: / / www.academie-agriculture.fr (accessed on 5 October 2018), https: / / www.alternativesforestieres.org (accessed on 5 October 2018)), and using the mapping of carbon projects available at https: / www.cnpf.fr/n/nos-partenariats-carbone/n:2493 (accessed on 5 October 2018)). Second, the selection of study areas was guided by socialecological considerations so as to retain two local initiatives that were similar in scope, partnership structure, and objectives. We did not aspire to cover the entire range of French forested regions or carbon offset organizations.

We chose two nonprofit organizations from two different regions: Sylv'ACCTES founded in 2015 and Normandie Forêver (hereafter, NF) founded in 2017. The study area of Sylv'ACCTES is in the Auvergne-Rhône-Alpes region, which has a long history of fuelwood exploitation. As one of the regions with the highest standing volume, it is dominated by a mixture of coniferous species in the mountains and broadleaved beech (Fagus sylvatica L.) and chestnut (Castanea sativa Mill.) in the plains [31]. By contrast, the second study area in Normandy is a coastal hilly area with a few forested patches of broadleaved beech and oak (Quercus robur L. and Quercus petraea (Matt.) Liebl.).

Throughout the article, interviewees are denoted by their anonymization number preceded by "S" or "NF" for Sylv'ACCTES and Normandie Forêver, respectively (for an overview, see Appendix B Table A2).

\subsection{Data Collection}

We carried out 14 face-to-face, semi-structured, open-ended interviews in November and December 2018 (Appendix B Table A2). We aimed to have a representative and pro- 
portional set of interviews for the two nonprofit organizations, balanced by their regional weight and level of activity (11 interviews took place in Auvergne-Rhône-Alpes and 3 in Normandy). Interviewees included forest managers, scientific committee members, financial partners such as public bodies and state agency officials, and forestry experts. Each interview followed a similar grid (Appendix B) consisting of the following: (i) a general description of the interviewee's role, objectives, and experience in the organization; (ii) the interviewee's view about the organization's ability to create bonds between stakeholders; and (iii) the interviewee's vision about the impact and potential development of the organization in the future. If not spontaneously mentioned by the interviewees, we also asked them about the implementation of the official "low carbon certification" (LCC) recently launched by the French Ministry of the Environment and its effect on the organization.

We recorded and fully transcribed the interviews, which lasted between 1 and 2.5 $\mathrm{h}$. We supplemented them with a review of the forestry press with a focus on mitigation projects (the newsletters are listed in Section 2.1), the websites of Sylv'ACCTES and NF ( https:// sylvacctes.org and http:/ / www.normandieforever.org, both accessed on 5 October 2018), as well as their preliminary reports on carbon accounting, operational charters, partnership leaflets, or financial information. In the following, any results without an interviewee number are sourced from this complementary documentation.

Our analysis aimed to understand the content of the offset contracts and their framework, namely the regional constraints of NF and Sylv'ACCTES, how they developed their organizational processes (distribution of decisional power between stakeholders, jurisdictional form, spatial and temporal scales, financing, etc.), and the importance given to carbon mitigation by the contractors (e.g., methodological soundness accounting for GHG mitigation). We thus developed a qualitative analysis grid (Appendix $C$ to tag and evaluate the transcription of each interview depending on the above items. After its completion by one author, the characterizations were crosschecked by a second author to avoid arbitrary classifications.

\subsection{Data Analysis: Methodological Approach}

We considered that the conceptual framework of Barnaud et al. on ES, social interdependencies, and collective action [30] was the most appropriate to investigate the efficiency, sustainability, and multifunctionality of NF and Sylv'ACCTES. Indeed, ES are at the core of this framework, which stresses how ES providers, beneficiaries, and intermediaries evolve in an "action arena" made of synergetic, antagonistic, or neutral interdependencies. The interdependencies can relate to different ES providers (e.g., private landholders, public forest managers), ES providers and beneficiaries (e.g., forest managers whose stand regeneration suffers from the overgrazing of boars and deer, hunters who are responsible for preventing the overpopulation of game animals), and ES beneficiaries (e.g., motorcyclists, hikers). These interdependencies are reshaped by changes in management decisions that modify ES and by new trade-offs in the interests of forest stakeholders. Intermediaries promoting collective actions such as NF and Sylv'ACCTES also contribute to the permanent restructuring of these social relationships. In the case of carbon offsetting, the analysis of the action arena should embrace four key dimensions: (i) stakeholders' representation of the FSES in light of carbon storage (i.e., "cognitive framing"); (ii) the spatial and temporal levels of organization at which carbon storage occurs; (iii) existing formal and informal institutions regulating carbon storage; and (iv) power relations between FSES stakeholders.

Rooted in Ostrom's work, this social-ecological framework accords with the conflictfree situations of NF and Sylv'ACCTES, in which carbon storage is seen as a public good and not as a product to be sold on carbon markets. To best apply this interdisciplinary conceptual framework, our research team was comprised of two ecologists, a social scientist, and an economist. This framework operates best in situations without open conflict where the emerging organization stems from a collective action around a public or common good (i.e., "a voluntary process of cooperation among various stakeholders, users, and managers addressing a common ES management problem in a given territory" [30]). We, therefore, 
discarded other conceptual frameworks such as the theories of non-state market-driven governance [32].

\section{Results}

To facilitate the comprehension of this section, Figure 1 summarizes the general functioning of the two nonprofit organizations: voluntary candidates, either private companies or public bodies, become members of the carbon offset organization after agreeing to its ethical conditions. They provide funding that is managed by forest practitioners. The organization then contracts carbon offsets with forest landholders.

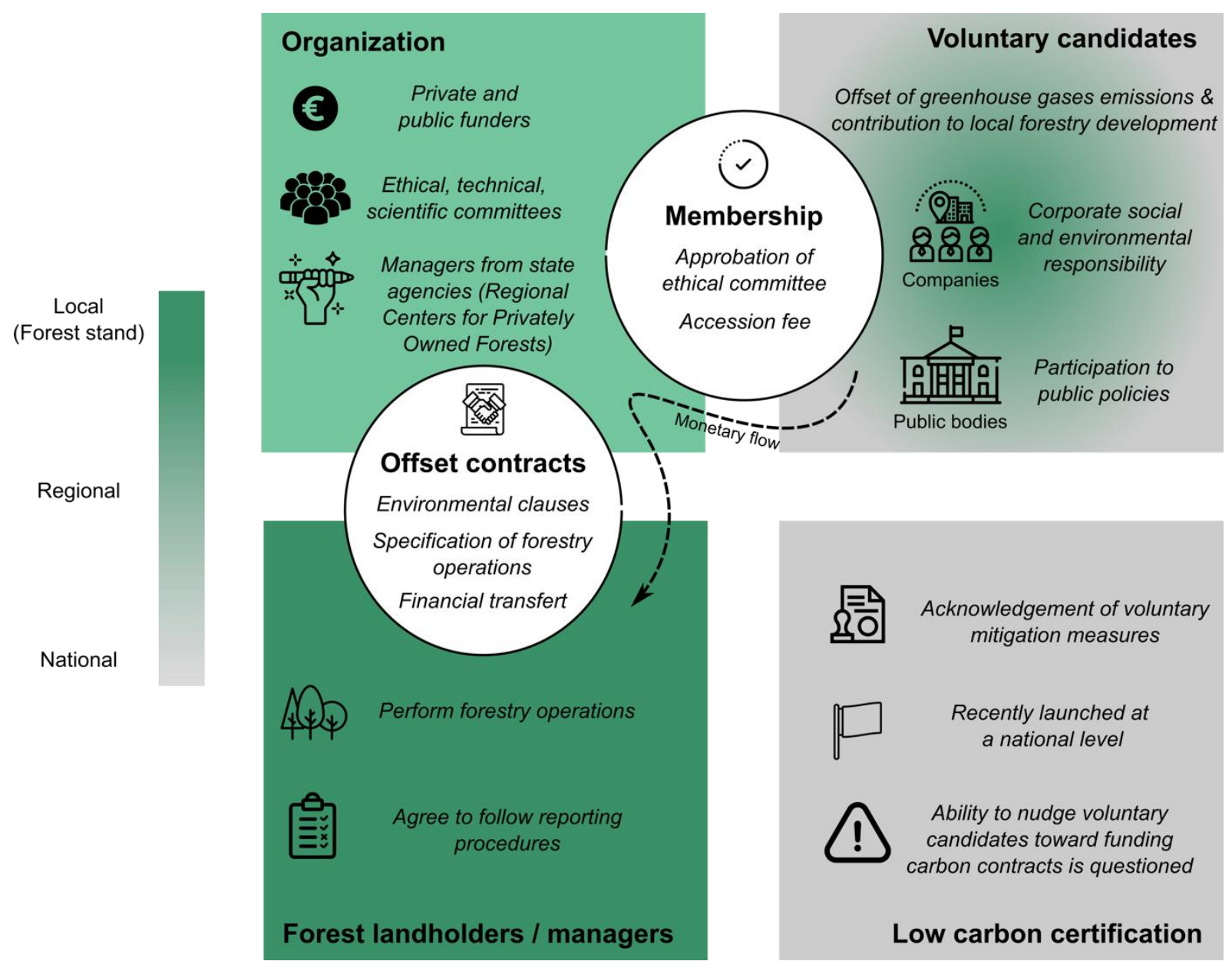

Figure 1. Internal functioning of the organizations offering voluntary carbon offset contracts.

\subsection{Offset Contracts to Increase Carbon Storage}

Offset contracts given by Sylv'ACCTES and NF fund the forestry operations of forest landowners provided that they respect the technical specifications (Figure 1). For instance, afforestation, deforestation, or reforestation are not eligible technical itineraries with Sylv'ACCTES; its contracts instead favor an evolution toward improved forest management (e.g., introduction of species mixtures rather than monospecific stands). Sylv'ACCTES also takes local hazards into account in order to exclude any detrimental effects on the local populations. In a flood-prone area, for instance, the funding of a project was subjected to the conservation of a continuous forest cover. Contrary to Sylv'ACCTES, NF allows a diversity of forest operations (e.g., clear-cut harvesting and replantation), as long as they occur in forest stands in which timber sales do not cover the cost of forestry operations. This difference may be due to the inappropriate planting of tree species given the local 
conditions or previous parasite attacks decreasing the value of the trees, among others. Sylv'ACCTES excludes contracts for forested surfaces under 2 ha [33].

To gauge how much carbon would be stored in the forest stands included in the offset contracts, the scientific committees of Sylv'ACCTES and NF developed reporting methods: "We have a scientific committee whose job is to make calculations and validate them, but also to confirm or refuse the proposals of forestry sites" (NF1). Prevailing issues around the reporting methods related to the heterogeneity, uncertainty, and impermanence of forests' capacities to store carbon as well as the additionality of the offset contracts.

First, the two organizations need to account for the heterogeneous soil, climate, or tree conditions of the stands. The reporting methodologies usually calculate the amount of carbon saved as the difference in carbon stored between a baseline scenario and a reference scenario. For both organizations, the baseline scenarios (no offset contracts) correspond to the management practices currently in place in the forest stands-for instance, the non-management of decaying stands for NF. Reference scenarios (with offset contracts) are the management of even-aged plantations for NF, while they are chosen among local forestry practices for Sylv'ACCTES (e.g., intensive even-aged forestry) (S1, NF1). Forest experts and ecologists selected practices with an added value for carbon mitigation such as the transition from even-aged forests to species- and age-mixed forests.

Second, the reporting methods need to account for potential carbon mitigation losses due to calculation uncertainties and stochastic natural uncertainties. Sylv'ACCTES retains estimations of carbon storage based on the most optimistic climate scenarios. Once calculated, only $80 \%$ of the carbon storage estimation is considered: in this case, if a project suffers from unexpected carbon leakage, it is assumed that the $20 \%$ uncounted carbon from all other projects can compensate for the mitigation shortfall. This methodology was patented under the name "Potential Mitigation Gain" (www.sylvacctes.org/les-indicateurssylv-acctes/, (accessed on 5 October 2018). NF adopted a similar strategy: to compensate for the potential carbon losses, $15 \%$ to $20 \%$ of the carbon stored is set aside in every calculation (NF1).

Third, the two carbon organizations aim to avoid carbon leakage during the engagement period of the offset contracts (10 years for Sylv'ACCTES and 20 years for NF). Only $\mathrm{NF}$ introduced a replanting clause into the contract in the event of carbon release following a natural hazard (e.g., parasite outbreaks, fires). The impermanence of carbon storage can also stem from contract violations if a forest owner harvests trees before the term of the contract. If the contracted activities are not properly completed, both organizations impose financial penalties-contractors are warned in advance about the possibility of verifications. Sylv'ACCTES dedicates a specific budget to conducting verifications (S1). For financial reasons, NF decided to verify the process internally rather than through external certification: "For us, the certification costs were too high to certify a project on the voluntary mitigation market" (NF3).

The fourth issue of the reporting methodology—additionality—was viewed as very delicate. Two approaches dealing with the issue of non-additionality are found in the literature [23]. The first is to accept the extent of non-additionality in the design of mitigation measures using "non-additionality buffers" among others (hence, additional to the uncertainty buffers). These buffers can be material, with the reduced counting of the carbon stored by the mitigation project, for instance, by setting aside $20 \%$ of GHG emissions of an offset project. Otherwise, buffers can be based on an insurance system: in the case of the disclosure of a non-additionality flaw, a saved part of the credits is dedicated to implementing complementary mitigation projects. The second approach used to ensure additionality is to have a contract framework that allows for a case-by-case analysis of the non-additionality risks. Sylv'ACCTES and NF chose the second option, with NF even adding an additionality clause to the offset contracts: "I hereby certify to the best of my knowledge that the funding provided by Normandie Forêver had an active and incentivizing role in my reforestation action for this stand, which had been caught in a forestry deadlock." 
Thanks to its offset contracts launched between 2016 and 2019, Sylv'ACCTES has participated in forestry operations over a surface of $4000 \mathrm{ha}$, split across 20 different forest stands in Rhône-Alpes. Despite its later start in 2018, NF's contracts have already supported forestry operations over 20 ha. NF now aims to reforest 1000 to 2000 ha of forests per year. The main concern of many interviewees was thus not the relevance of the offset contracts but rather the need to recruit enough forest landowners: "If many people wanted to fund carbon offsetting, but there weren't enough owners, then we would be headed for trouble" (NF2). A Sylv'ACCTES' member explained that offset contracts are not given full consideration by private owners and that private forests only represent $20 \%$ of grantees, with the remaining $80 \%$ used for municipal forests (S1). A NF interviewee also pointed to the overrepresentation of owners aged over 60 years who represent twothirds of forest owners: "We are among a relatively old group of people, so it is difficult to speak of 20,30 , or 100 years into the future with someone who is already 80" (NF2). Thus, both organizations are in the process of hiring a permanent employee devoted to contacting landholders.

Based on their experience, Sylv'ACCTES and NF members were invited to participate in the creation of the national "low carbon certification." Prior to 2018, the lack of a carbon standard in France led to the search for a reliable tool for voluntary carbon offsetting in order to meet societal expectations regarding GHG mitigation. Although some interviewees acknowledged the value of this initiative, they questioned the technical feasibility of this results-oriented LCC: "The problem with carbon projects is that we must do what is called a proof of additionality to prove that what we do is better than baseline. And in forests, well ..." (S1).

\subsection{Carbon Organizations: Pursuing Multifunctional Forestry to Attract Funders}

To provide appropriate financing for their offset contracts, Sylv'ACCTES and NF depend on the financial support of both private and public bodies, attracted by communication campaigns focused on the mitigation of GHG emissions. For instance, NF's leaflet includes many such expressions ("A concrete and guaranteed commitment to reducing $\mathrm{CO}_{2}$ emissions by local reforestation"), while the very name of Sylv'ACCTES stands for "Sylviculture d'Atténuation du Changement Climatique et Services Ecosystémiques" (French for "Silviculture for the Mitigation of Climate Change and Ecosystem Services"). Increasing carbon storage and sequestration in forests was an objective shared by all public and private funders of the associations. Public funders such as towns, cities, and regional councils expressed their interest in forest operations to improve GHG mitigation: "Sylv'ACCTES has another advantage: working with carbon throughout the entire wood lifecycle, and in addition to the societal demands, this is a strong political objective at every level" (S3). In the same vein, the creation of NF was driven by companies wishing to mitigate their carbon emissions: "The sustainable development club-for companies that are very involved in CSR, it is a network. They wondered how they could reduce carbon emissions, and they were looking for local mitigation solutions" (NF1). In Normandy, private funders even prioritize carbon mitigation over other considerations. The aim is to stay as effective as possible and avoid interference from other issues, because when there are "expectations other than carbon such as biodiversity, environment, landscape, or satisfying locally elected officials, it just becomes much more political. By staying focused on carbon, we chose to prioritize it-without removing the rest, we just prioritized carbon" (NF1).

To put this interest into funding, NF relies on two mechanisms that are open to any private or public structure: an annual membership fee of $150 €$ (Figure 1), and a contribution to NF of $14 €$ per carbon ton emitted annually by the new member. To avoid greenwashing or conflicts of interest, membership is subject to an ethical code and the decision of the ethical committee: "As firms are highly invested in CSR, they want it to be a real process of carbon mitigation, so we established rules to join Normandie Forêver" (NF1). For Sylv'ACCTES, a membership fee is the first source of income and demonstrates a willingness to contribute to the organization's decisions (Figure 1). Second, the organiza- 
tion benefits from the monetary support of its public and private funding members at a regional level (Auvergne-Rhône-Alpes region, city of Lyon, and Neuflize Bank) and at a smaller scale (local businesses contribute to funding local forestry operations). In addition, Sylv'ACCTES benefits from an asset that NF does not have. Whereas both are nonprofit organizations, only Sylv'ACCTES is recognized to be of general interest by the French state due to its commitment "to the defense of the natural environment" (Sylv'ACCTES, 2018b). Consequently, Sylv'ACCTES benefits from a system of tax exemption delivered by the fiscal administration. Hence, the organization is allowed to deliver tax receipts that provide a $60 \%$ tax exemption for any donation. In other words, a company giving $100,000 €$ only incurs a 40,000 € expenditure after the tax credit. Application for membership is once again subject to an ethical committee.

Whether NF and Sylv'ACCTES like it or not, their funders are also attracted by the opportunity to improve other forest ES through the carbon offset contracts. Business funders viewed Sylv'ACCTES and NF as an opportunity to offset their carbon emissions and simultaneously strengthen their social and environmental responsibilities at a local level. The corporate funders of Sylv'ACCTES are mainly motivated by the positive social and economic consequences of forestry operations, emphasized as one of the reasons for participating in the regional development of the forestry sector: "Bringing together private firms in or within territories: this is a stronger message than saying 'you love forests, so give to forests'" (S11) or "What we want to do is to create a short circuit. We have the local authorities, local foresters, and local companies accompanying the management of a natural resource toward something more virtuous" (S1).

For regional and local authorities, NF and Sylv'ACCTES open an additional avenue to reinforce their forest-based policies such as the economic development of the timber industry, the reinforcement of the renewable energy sector, the promotion of open-air leisure activities, and so on. This holds particularly true regarding the increased wood mobilization, which is an important motivation for regional councils and cities to fund carbon organizations. The regional branch of the Agency for the Environment and Management of Energy (ADEME), which was instrumental in the launch of NF, explained: "In the end, mitigation is not everything. For us, it's just a good reason to influence other fuelwood policies" (NF3). At a smaller scale, several cities in Normandy joined NF, as they are currently developing collective heating facilities: "We wanted to mobilize a lot of extra wood, mobilize wood-fired heating plants in private forests" (NF3). For Sylv'ACCTES, the regional need for fuelwood heating was one of the reasons for public funders to become involved. The Auvergne-Rhone-Alpes region has a strong culture of fuelwood heating that continues to develop, and it encouraged an organization that secured the local and sustainable production of fuelwood: "The 'Grand Lyon' metropolis had problems with provisioning their wood-fired heating plants. We also worked with territories on timber production, so there was this interesting rural-urban link" (S10). Along with fire heating, the rural-urban link was depicted by both associations as a communication support that strengthened the relationships between forest operators, local companies, and inhabitants: "From the perspective of Sylv'ACCTES' governance, its major interest lies in the creation of a local dialogue" (S7).

\subsection{Sustainable Timber Production: A Key Motivation Underlying Offset Contracts}

Along with carbon storage and other forest ES, increasing or securing timber production emerged as a key underlying motivation in the creation of new forest intermediaries oriented toward carbon storage. The involvement of the Regional Centers for Privately Owned Forests (CRPF in French) in Normandy and Auvergne-Rhône-Alpes was a determining factor in the foundation of NF and Sylv'ACCTES, as mentioned on their websites, in many interviews, and in the NF offset contracts; indeed, CRPFs are public bodies that promote the indirect stimulation of the timber industry through increased wood mobilization in private forests [31]. For NF especially, producing wood was a key issue, since regionalized forest growth models can predict a gap in wood production due to the unbal- 
anced age structure of forest stands. To supply the missing age category, the Normandy CRPF viewed NF as a relevant interface to pay for the clear-cut and replanting costs of decaying and unproductive stands, thus avoiding a potential problem linked to timber and fuelwood provisioning in the coming decades.

In line with the CRPFs, private landholders and public forest managers who enter into an offset contract consider the funding of Sylv'ACCTES and NF to be a relevant solution for funding timber production. This holds true for the funding of forest operations that would otherwise not occur: "For us, the starting point was mobilizing the wood of poor forest stands" (NF2). Yet it also applies to operations aimed at improving the quality of harvested wood: "The idea of Sylv'ACCTES is to really improve the value of the timber" (S5). In both cases, the funding amount of the contracts is not intended to fully cover the costs of the forest operations but is rather seen as an incentive for forest landowners to set them up, as underlined by interviewee NF3: "The amount was evaluated so that it would be large enough to commit to the program." To determine how much of the costs of forest management would be reimbursed, Sylv'ACCTES decided to focus on forest expenditure independently of carbon markets, with the offset contracts funding $40 \%$ of the operations. By contrast, NF decided to set the amount of funding based on the market price of a carbon ton and calculated that each hectare replanted after clear-cutting could store a certain amount of carbon, equivalent to $2000 €$ per hectare (capped at a maximum of $30 \%$ of the costs). NF explained that the funding requirements should be more attractive than public subsidies: "It has to be simple and not supported by EAFRD [European Agricultural Fund for Rural Development], relatively fast in reaching a decision, and exploitable for the landowner" (NF2).

While timber production was an important issue in the relations between forest landholders and the carbon organizations, Sylv'ACCTES and NF remained vigilant about its sustainability, especially regarding the protection of natural habitats. To be eligible for the offset contracts, forest landowners had to comply with environmental prerequisites. As proof of commitment to biodiversity, NF and Sylv'ACCTES require an official document that is mandatory in France for properties over 25 ha (and optional below), certifying that the target stands are sustainably managed. As an additional environmental condition, NF requires a sustainable management certification delivered by the Program for the Endorsement of Forest Certification (PEFC) or the Forest Stewardship Council (FSC). Sylv'ACCTES does not demand environmental certifications for a forest stand but instead requires that at least $30 \%$ of its surface has a species mixture, with at least five old-growth trees per hectare. To monitor the ecological impact of its offset contracts, Sylv'ACCTES patented an indicator known as "Potential Biodiversity Gain" (www.sylvacctes.org/lesindicateurs-sylv-acctes/, (accessed on 5 October 2018). The indicator developed from early discussions between Sylv'ACCTES and members of environmental organizations, who were invited to be part of the organization's scientific committee and contribute to the design of the environmental specifications of the offset contracts.

To improve the funding success of forest operations, Sylv'ACCTES and NF tried to reduce the detrimental effects of timber production on the contribution of the forests to the landscape. Several interviewees mentioned their fear of the social pressures linked to forestry operations, which is commonly expressed by inhabitants in their rejection of tree harvesting. Interviewee NF2 described a public conference on forestry held in Normandy: "Several people expressed their feelings for the trees, and we saw that many people were there to defend the trees and stop an overly interventionist approach by limiting the number cut down." In anticipation of such claims, the communication strategy of NF stressed the positive outcomes of forestry operations for carbon mitigation or local employment, and not only the technical aspects. Information boards were displayed at the site of each supported operation, and forest owners who signed the offset contracts also acknowledged the right of funders to visit the forest stand. 


\section{Discussion}

NF and Sylv'ACCTES have emerged as new intermediary forest organizations, aiming to bring together forest managers (carbon storage providers) and forest ES beneficiaries around carbon storage projects. Although the formal institutionalization of NF and Sylv'ACCTES is undeniable, their strategy to manage efficient, sustainable, and multifunctional projects for forest carbon storage must be questioned in the light of the actual outcomes. Figure 2 illustrates the discussion using the conceptual framework of Barnaud et al. for ES, social interdependencies, and collective action.

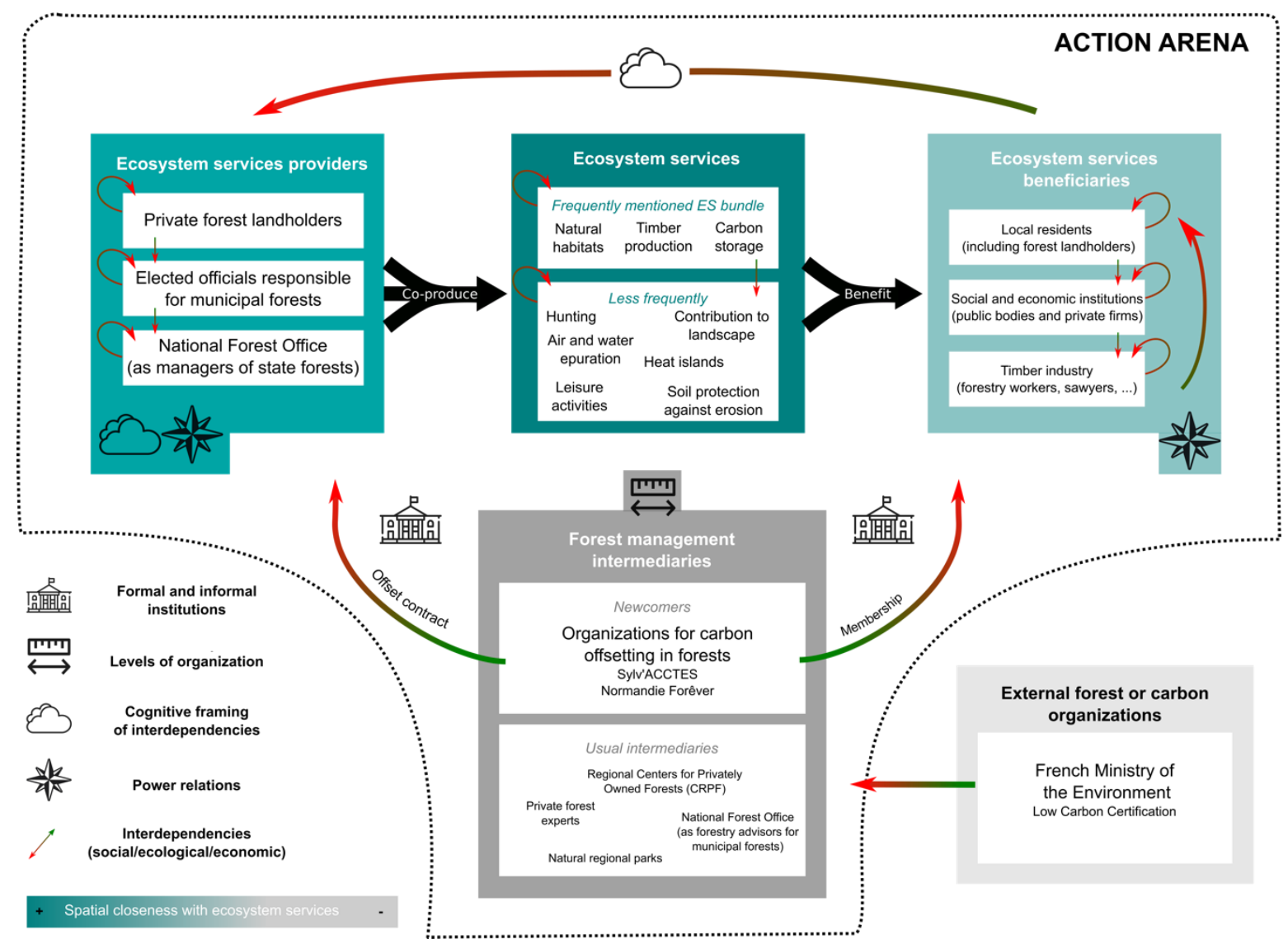

Figure 2. The conceptual framework for ecosystem services (ES), social interdependencies, and collective actions applied to French forest socio-ecosystems.

\subsection{On the Efficiency of Carbon Storage Organizations}

We posit that the efficiency of the carbon projects initiated by NF and Sylv'ACCTES does not lie in their new methodological approach to overcome the four challenges of carbon storage but rather in their design of operational contracts to increase the number of participating landholders. Conditioning the financial aid to an obligation of means (technical specifications) and not to an obligation of results (reaching a given amount of stored carbon) was a strategic choice of both NF and Sylv'ACCTES to avoid deterring forest ES providers, which enabled them to efficiently recruit forest managers.

Even so, NF and Sylv'ACCTES chose three proven solutions to design forest contracts that efficiently overcome the usual challenges of carbon storage. Based on the recommendations of their scientific committees, they opted for a "physical" buffer system as well as ex-ante and in-itinere verifications. The physical buffer system reports less carbon storage than initially calculated, which is a common means to prevent heterogeneity and uncertainty issues. A carbon reserve buffers deviations caused by heterogeneous and uncertain forest conditions based on the difference between the amount of carbon stored after the 
contract closure and what was anticipated in the reference scenario $[7,23,34]$. Uncertainties in the calculation parameters can stem from their inherent stochasticity (e.g., local climate), entanglement (e.g., tail dependence effects strengthened by climate change; [15]), a lack of reliable data (e.g., soil condition, browsing pressure), not to mention the knowledge gap regarding phenomena that are only now coming to light (e.g., storage capacity of upper soil horizons or old-growth versus recent forests; [35-37]). The second solution prevented additionality issues. Both organizations chose an ex-ante evaluation of applicants' motivations to sign the offset contracts. This case-by-case assessment aimed to discard candidates who would conduct forest operations regardless of the offset contracts. The two organizations also planned in-itinere verifications of the permanence of the subsidized projects. Their approach, used in many other countries $[23,38,39]$, aims to include the transaction costs of impermanence verifications in their estimated budgets. The organization either funds an external certifying body such as the Verified Carbon Standard [40] or pays for the costs of verifying the contracts itself. Only NF introduced a replanting clause in its contract in the event of destruction following a natural hazard, which was certainly motivated by its objective to prepare the timber industry for the upcoming decades. The lack of ex-post verifications of the efficiency of the offset contracts (for instance, by measuring how much additional carbon will be stored) underlines the preference of NF and Sylv'ACCTES for means-oriented, not results-oriented, offset contracts.

The preference of NF and Sylv'ACCTES for means-oriented contracts emphasizes their strategy of focusing on the second limiting factor of offset contracts, namely the reticence of landholders to commit to their program. Subsidies for forestry operations can be scarce and sometimes so complex that they deter many forest owners from applying for them. Both public foresters and private owners struggle to balance their management expenses with timber incomes. Public foresters working for the National Forests Office are in charge of the management of national forests but have to reduce their expenditure [41]. Private foresters do not strive for profit at any cost, although they can no longer rely on traditional subsidies to keep their budget balanced [42]. Known as the National Forest Fund, a funding program was launched in the aftermath of World War II to boost wood production in order to rebuild the country. However, this program ended in 2000, thus inducing a loss of financial incentives for private owners [43]. The solution of the offset contracts proposed by NF and Sylv'ACCTES partially overcomes the economic impediment to forest management. Compared with the national tax exemption known as DEFI (French acronym for "Dispositif d'Encouragement Fiscal à l'Investissement", meaning "fiscal measures supporting investment") piloted by the Ministry of Agriculture, which is also in charge of forests, Sylv'ACCTES contributes twice as much to the costs of sylvicultural operations (until December 2020, DEFI could refund up to $6250 €$ per capita for forest operations expenses [44]). Its engagement period is five years shorter (10 years vs 15 years for DEFI), and its minimum surface is half the size (2 ha vs. 4 ha for DEFI) [33]. Another key feature of the offset contracts is that they abide by the financial concerns of landowners and base the amount of the subsidy on the cost of the forestry operations. Strictly correlating an aid to international market prices for a ton of carbon dioxide would have created uncertainty and discouraged landowners, as observed in many REDD+ projects [40]. The meansbased design of the offset contracts of NF and Sylv'ACCTES ensured their legibility and visibility, thus increasing their appeal to forest owners. However, in spite of these attractive conditions, it appears that subsidy contracts are not given full consideration by private owners, who are a major target of NF and Sylv'ACCTES. Indeed, private forests cover $75 \%$ of forested areas in France, with the remainder being split between state forests and public entity forests [31]. One explanation may relate to the reluctance of private owners to engage in long-term contracts, even for 10 years, as observed in other voluntary forestry programs such as conservation programs [45]. Another non-exclusive explanation is that the French forest owners most interested in carbon mitigation tend to be the youngest and most educated ones [21], an underrepresented group among private forest owners [46]. 
The efficiency of the offset contracts in recruiting forest ES providers must therefore be assessed in the light of the recipient owners. Public forest managers are overrepresented, which reveals another obstacle to the activities of NF and Sylv'ACCTES: the long-standing problem of the ownership structures of private forests. The fragmentation of private forests, the ageing of their plentiful owners, and the share of absentee forest owners are internationally known to impede private investment in carbon offset contracts [38,39], and this equally applies to the French forest sector [46]. The efficiency of NF and Sylv'ACCTES to connect with forest ES providers is therefore not yet fully exploited, as both organizations mainly attract public forest managers. Municipalities owning forests find the offset contracts to be efficient. As they often struggle to balance their forest budgets, these municipalities welcome this additional funding source. Besides, elected officials now have an alternative forestry advisor with carbon organizations compared with their usual interaction with the National Forest Office. The new possibility of sharing critical financial, technical, or administrative knowledge about forest management reinforces elected officials' power of decision. In this regard, our findings further evidence how the emerging intermediaries of forest carbon storage impact the power distribution among forest ES providers.

At the time of writing, there were no ex-post evaluations of the offset contracts of NF and Sylv'ACCTES. Due care must therefore be paid to assessing their overall effectiveness in enhancing forest carbon storage. Yet we strongly believe that their science-based technical approach is certainly not counterproductive to enhancing carbon storage. On the contrary, it is presumably the best approach to efficiently recruit forest ES providers in times of uncertainty, especially since the means-oriented (and not results-oriented) conception of the offset contracts does not fundamentally change the distribution of economic power among FSES stakeholders, thus avoiding potential conflicts.

\subsection{Sustainability of Carbon Offsetting Dependent on Its Multifunctionality}

Multi-objective forest operations are most often inconsistent with a management approach geared toward only one ES such as carbon storage, unless an appropriate spatial resolution is found [47]. This situation is commonly illustrated with management intensification for timber production, which can contradict biodiversity conservation or water quality preservation, for instance [8,27-29]. Consequently, NF and Sylv'ACCTES paid attention to the environmental, social, and economic outcomes of forest management to avoid conflicts of use with other forest ES providers or beneficiaries.

To ensure their environmental sustainability, NF and Sylv'ACCTES called on environmental partners to help develop clauses for environmental safeguards in the offset contracts. NF required a sustainable management certification delivered by PEFC or FSC, a widespread practice used to account for environmental concerns [48]. Sylv'ACCTES does not use environmental certifications but instead requires a species mixture covering at least $30 \%$ of the forest surface and at least five old-growth trees per hectare. Neither of these criteria proved to be challenging for forest owners, as many stands already meet these requirements in the Auvergne-Rhône-Alpes region [31]. We assumed that establishing such environmental safeguards was a genuine requirement for NF and Sylv'ACCTES and a key to strengthening the communication strategy around carbon mitigation and avoiding any pressure from environmental organizations.

The social sustainability of NF and Sylv'ACCTES relies on the non-partisan cognitive framing of the offset contracts, portrayed as a winning combination of various interests that goes beyond party lines. This ensured the stable launch and expansion of the organizations, as illustrated at the very beginning of Sylv'ACCTES. A political shift at the head of its region could have halted the financial contribution of the regional council, but the newly elected regional officials maintained their support. In our opinion, the non-partisan cognitive framing of the offset contracts went hand in hand with the communication efforts emphasizing the neutral or synergetic rearrangement of social relationships due to the forest operations. Involved in only a limited manner with the nonprofit organizations, hikers and local inhabitants could read information boards championing the positive role 
of forest management in providing them with forest ES (especially carbon storage). This defused any potential conflict with these beneficiaries of the landscape and recreational forest ES. When more actively involved, the forest owners increased their awareness of their contribution to the mitigation of climate change. This socially rewarding position was prone to avoid conflict and even convert them into supporters. Similarly, the attention paid to the environmental sustainability of the contracts and the communication centered around their positive economic and regional outcomes were key aspects for securing the recruitment of new funders. This started a virtuous circle in which the positive labeling of local businesses and public entities (e.g., mayors) that supported NF and Sylv'ACCTES boosted the arrival of new funders from beyond the "usual" forest ES providers. This strategy of NF and Sylv'ACCTES - "prevention (of conflict) is better than cure"-is also illustrated by their way of dealing with the greatest risk of social conflict, namely the current configuration of the offset contracts that rewards the "black sheep." To avoid the usual funding of forest stands with the worst practices of GHG mitigation, eligibility criteria might progressively change to follow the evolution of mitigation policies-with a risk of subsequently lessening the interest of forest owners in this type of incentive.

The positive outcomes of the offset contracts on social and economic forest ES were strong incentives to attract public bodies and private companies eager to voluntarily offset their GHG emissions. They also contributed to securing support from the traditional forest management operators. The respect for the funders' core values and organizational self-interest is known to expand membership [49], a mechanism even bolstered by the inclusion of environmental safeguards to reduce the reputational risks of "greenwashing." By broadening the range of potential funders to private businesses and public entities, the carbon organizations need to consider the multitude of forest ES to unlock additional financial sources based on mitigation. In the case of Sylv'ACCTES, this can be seen through the recognition of general interest, which does not acknowledge forest management but is rather motivated by the "defense of the natural environment." The tax exemption was a strong lever to ensure the funding of the organization's subsidy system. To the best of our knowledge, this type of financial structure is unknown in the forestry sector and may be expanded, as stressed by the desire of NF to be recognized to be of public interest. However, we argue that the support of both public and private funders is a powerful lever for funding forest management, although it is still double-edged. Concerns can be raised regarding the gradual development of asymmetric power interdependencies between ES providers and ES beneficiaries, with a shift of forestry funding from the EU and state-based subsidies to private and regional-based funding. Voluntary contributions to the funding of forest management should not exceed a certain threshold in the eventuality of a funder withdrawing support, because it could or would not maintain funding. The same applies to NF, for which offset contracts should first aim at solving the regional timber issue; hence, development further afield is currently not given much attention, or at most, in neighboring regions. Funding issues could therefore arise once this problem is solved.

\subsection{Territorial Scale Conditioning the Efficiency and Sustainability of Carbon Offsetting}

As raised in most interviews, the territorial scale of the carbon organizations was deemed essential for their efficiency and sustainability. Both NF and Sylv'ACCTES achieved a specific cognitive framing around the social-ecological interdependencies between forest ES providers and carbon offsetters. For instance, they outlined the regional benefits of forest climate services that connected local funders and forest ES providers (e.g., [50]). In other words, they reduced the social distance between them, which is an important feature of bottom-up collective action by decreasing the transaction costs of coordination [51]. For instance, the original clustering of the two carbon organizations with public entities and CRPFs brought a form of insurance against potential greenwashing allegations against the private funders. A consensus is now emerging in the carbon organizations regarding the importance of regional embedding for their development, which explains the caution shown in terms of expanding to other regions so as not to lose 
operationality. Indeed, while collective action operates well when social distances are small, scaling-up to higher spatial levels of organization favors market- and state-based institutions [30]. The same applies to the local adaptation of the concept of multifunctional forestry $[47,52]$.

The issue of securing current projects and expanding is now arising, especially since a national LCC was portrayed as an incentive for voluntary mitigation projects. Inspired by other EU initiatives such as the woodland carbon plan in the UK [53], the Ministry of the Environment tasked the semi-public Institute for Carbon Economics (I4CE) with developing a voluntary mitigation certification known as the "low carbon certification," which was created to contribute to the Ministry's carbon neutrality policy for 2050. Officially released in November 2018 by the Ministry of the Environment, the LCC consists of a checklist of general features similar to international standards [13]. According to the LCC, offsets must be real, measurable, verifiable, and supplementary [54]. The LCC is also supposed to reject projects with "potentially significant negative impacts from an environmental and socioeconomic perspective" [51]. Broadly, the LCC encourages bottomup initiatives. For the forestry sector, any field practitioner can launch a project. Yet three major limitations in the LCC process arise from the rifts between top-down international mitigation standards and field-based indicators. First, as with Sylv'ACCTES and NF, the results-based additionality, exactitude, and exhaustivity principles are too demanding given the numerous knowledge gaps and uncertainties surrounding carbon mitigation. Second, the engagement period of 30 years was chosen in line with the 2050 target for carbon neutrality, but this does not align with the temporality of foresters nor with the need for businesses to assess the impact of their funding in timeframes that are compatible with their CSR policies. This is a problem for organizations such as NF, which aim for a positive carbon balance in 70 years instead of 30 years. Third, as explained in its official description, no financial incentives are guaranteed by the certification [51]. The only incentive for using the LCC is gaining a good reputation once granted. Paradoxically, the certification encourages bottom-up approaches that nurture mutual trust between project participants, the same trust that absolves them from relying on external certification. Similar observations have been made in other national contexts [40].

Only the coming years will tell if locally based mitigation projects will require the LCC to provide a guarantee to potential corporate funders with little knowledge of offset processes. This would lead to a switch from local funders located near the carbon organizations to nationwide firms trying to offset their GHG emissions using the LCC to anticipate and avoid future regulatory burdens or attract investors [49]. We argue for the coexistence of bottom-up carbon organizations and carbon certifications such as the LCC, so as to complement (and not replace) means-oriented forest intermediaries with results-oriented mitigation tools. The EU, for instance, places a strong emphasis on reporting the results obtained from subsidies, with less importance given to the means used [55].

\section{Conclusions}

The outcomes of global changes on forest management are manifold, as illustrated by our case study on the plural effects of GHG mitigation. We outline here how offset contracts succeeded in cementing bonds between professionals tasked with the development of forestry operations, private and public structures interested in GHG mitigation, and landowners struggling to fund the management of their forests. In our opinion, the two carbon organizations did not innovate in terms of the technical operations adopted to store more carbon in forests - they simply retained the best practices known to date. Their most striking feature is the development of collective action in the FSES based on a forest ES other than timber production.

A few key points can be learned from this study and used for the development or evaluation of further collective actions of carbon storage in FSES.

First, we argue that, regardless of the national or regional context, considering the singularities of the FSES - especially its multifunctionality-and its stakeholders is a key 
element. Indeed, the best way to strengthen voluntary bottom-up projects is to build trust by protecting the interests of members and their work culture [51]. The efficiency and sustainability of the intermediary forest organizations therefore depend on integrating the carbon mitigation challenges with the issues of concern of their contributors and beneficiaries. Here, we recommend carbon organizations to specify the main objectives of their carbon offsetters and beneficiaries: are they willing to strengthen their environmental responsibility? Do they want to open a new funding channel for forestry operations? How long are they prepared to participate? Etc.

Second, the social and economic sustainability of the offset contracts also relies on the prevention of conflicts among and between forest ES providers, forest ES beneficiaries, and other forest management intermediaries (e.g., natural regional parks). Conflict prevention also stemmed from social learning about the interdependencies of all the actors in the action arena [56]. While the FSES can be susceptible to various open conflicts because of the incoming subsidies [40], our case studies encountered relatively few confrontations despite tensions around the prioritization of forest ES. To avoid an explosive situation in which timber production or environmental conservation is hindered by the offset contracts, NF and Sylv'ACCTES worked for collective governance to balance the power distribution between FSES stakeholders. By bringing together the representatives of the different groups of the FSES (e.g., members of environmental organizations, elected officials), they opted for what may seem to be a "weak consensus" regarding multifunctionality. According to this vision, the enhancement of forest ES (carbon storage) stops where another (timber production, habitat preservation) begins. More specifically, we recommend proactively inviting any stakeholder showing interest in the carbon offsetting to take part in the process [5]. If required, distinct discussion arenas can be initiated to prevent the reemergence of long-standing conflicts (e.g., ethical, technical, scientific committees).

Third, the intermediary carbon organizations made significant efforts for the cognitive framing of the offset contracts, thus proving their added value for every protagonist of the forest action arena. We assume that institutionalizing the link between carbon offsetters and public and private forest landholders is one of their main achievements. This exemplifies the social-ecological interactions between forest stakeholders across spatial and temporal levels. We posit that maintaining effective internal and external communications about the objectives, processes and results of forestry operations is paramount in boosting forest management for carbon offsetting.

We also draw the reader's attention to the potential weaknesses of the process. The strategy of enhancing carbon storage by effectuating small changes to forest operations on a maximum of different forest plots only works if multifarious forest owners and managers can be targeted. This strategy requires both a good knowledge of the structure of forest ownership [38] and communication skills to avoid presenting offset contracts as a panacea to fund forest operations. Indeed, foresters have shown their interest in the financial initiatives for environment services, especially in a context of rising climatic hazards. Currently, French forest landholders generate most of their forest-based revenues from timber sales (and in some cases, the lease of hunting rights), but these are at risk with the increase in climate hazards. It could be important to keep in mind that carbon subsidies are not intended to cover all the expenditure of forest management but rather to act as a lever for forestry operations along with incomes stemming from the valuation of other forest ES. Lastly, the state government should encourage voluntary initiatives to offset GHG emissions, although they should not forget that they are means-oriented, which contradicts their broader integration into results-oriented mitigation policies (e.g., REDD+ [16]).

Time is now needed to assess the actual contribution of these voluntary actions to the overwhelming issue of global climate change. However, they seem to be robust and serious, as shown by the consideration granted to forest operations that acknowledge the adverse effects of climate change. As a sign of the times, the effectiveness of intermediary organizations that promote carbon storage has gained national and international recogni- 
tion, as shown by the presentation of Sylv'ACCTES as a "nature-based solution" by the International Union for Conservation of Nature [57].

Author Contributions: Conceptualization, T.F. and L.G.; methodology, T.F. and L.G.; validation, M.T., N.F.-L.; formal analysis, T.F. and L.G.; investigation, T.F. and L.G.; resources, T.F. and L.G.; data curation, T.F. and L.G.; writing—original draft preparation, T.F. and L.G.; writing—review and editing, M.T. and N.F.-L.; visualization, T.F.; supervision, N.F.-L.; project administration, T.F.; funding acquisition, N.F.-L. All authors have read and agreed to the published version of the manuscript.

Funding: This research was funded by the French National Research Agency (ANR), grant number ANR-11-LABX-0034 as part of the "Investissements d'Avenir" Program (LabEx BASC).

Institutional Review Board Statement: Not applicable.

Informed Consent Statement: Informed consent was obtained from all subjects involved in the study.

Data Availability Statement: The data presented in this study are available on request from the corresponding author. The data are not publicly available due to privacy reasons.

Acknowledgments: The authors are grateful to the members of Sylv'ACCTES and Normandie Forêver for their willingness to share their knowledge. The article was improved thanks to the comments of two anonymous reviewers, to whom we are very grateful.

Conflicts of Interest: The authors declare no conflicts of interest. The funders had no role in the design of the study; in the collection, analyses, or interpretation of data; in the writing of the manuscript, or in the decision to publish the results.

\section{Appendix A}

Table A1. List of identified carbon projects. All websites were accessed online on September and October 2018.

\begin{tabular}{cc}
\hline Organization Name & Source \\
\hline Coeur de Forêt & https://www.coeurdeforet.com \\
\hline Collectif Bois 07 & https://collectifbois07.wordpress.com \\
\hline Duramen & https://www.duramen.org \\
\hline EcoTree & https:/ / ecotree.green \\
\hline ERE43 & https://www.ere43.fr \\
\hline Normandie Forêver & http://www.normandieforever.org \\
\hline Pur Projet & https://www.facebook.com/normandieforever \\
\hline Reforest'Action & $h t$ / www.purprojet.com \\
\hline Sylv'ACCTES & https:/ / sylvacctes.org \\
\hline
\end{tabular}

\section{Appendix B}

The overall objective of the interview grid was to describe the "forest carbon storage" action arena using the following categories:

- Structure and functioning of the organization: Does the carbon offsetting involve technical changes (e.g., new tools, sylvicultural management practices) or logistic and organizational changes (e.g., new organization in the relations and administration of forest industry)?

- Efficiency of carbon storage: What are the results of the projects? What are the indicators and references used to measure carbon storage (e.g., consideration of both above- and belowground carbon compartments)? 
- Sustainability of the organization: Is biodiversity an issue? If yes, how is it included in the forest operations geared toward carbon storage? How are the financial subsidies determined? Are they calculated based on carbon markets?

- Consideration for forest multi-functionality/cognitive framing: Along with carbon storage, which other ecosystem services/forest functions/uses are targeted? Which results matter the most? Do the different forest stakeholders and carbon offsetters share the same vision of forest management?

- Spatial and temporal dimensions of the organization: Will the organization endure in time (e.g., climate uncertainties) and space (i.e., can it be replicated in other territories, and if yes, what are the specific methodological tools for a given territory)?

- Stakeholders' interactions within the organization: How are the relations between actors organized? Is there anything novel about the way in which carbon offsetters and foresters interact (compared to the usual action arena of French forestry)? If yes, what is it?

- Power relations: How are the carbon storage organizations structured? Where does the executive power lie? Do they encounter the same deadlocks as those emphasized by traditional timber growers?

Table A2. Overview of the interviewees.

\begin{tabular}{|c|c|c|c|}
\hline Project & Anonymization Number & Sex (Male/Female) & Role in the Offset Project \\
\hline \multirow{11}{*}{ Sylv'ACCTES } & S1 & M & Cofounder and coordinator \\
\hline & S2 & $\mathrm{F}$ & Management of a forest where an offset project takes place \\
\hline & S3 & $\mathrm{F}$ & Member of the technical and scientific committee \\
\hline & S4 & M & Management of a forest where an offset project takes place \\
\hline & S5 & $\mathrm{F}$ & Management of a forest where an offset project takes place \\
\hline & S6 & $\mathrm{F}$ & Management of a forest where an offset project takes place \\
\hline & S7 & M & Member of the technical and scientific committee \\
\hline & S8 & M & Member of the technical and scientific committee \\
\hline & S9 & M & Funder (carbon offsetter) \\
\hline & S10 & $\mathrm{F}$ & Cofounder \\
\hline & S11 & M & Funder (carbon offsetter) \\
\hline \multirow{3}{*}{ Normandie Forêver } & NF 1 & $\mathrm{M}$ & Cofounder and coordinator \\
\hline & NF2 & $\mathrm{F}$ & Comanager of a forest where an offset project takes place \\
\hline & NF3 & M & Cofounder and funder \\
\hline
\end{tabular}

Table A3. Grid of the semi-directed interviews.

\begin{tabular}{|c|c|c|}
\hline Interview Category & Questions & Alternative Formulations to Relay the Question \\
\hline $\begin{array}{c}\text { Interviewee's relation to the carbon } \\
\text { offsetting organization }\end{array}$ & $\begin{array}{l}\text { - Which professional or life path brought you } \\
\text { to work with/in [name of the organization]? } \\
\text { - How did you become involved in [name of } \\
\text { the organization]? } \\
\text { - What actions have you initiated since } \\
\text { joining the project? }\end{array}$ & $\begin{array}{l}\text { - Could you talk about the beginning of the project and its } \\
\text { implementation? Or about the moment when you arrived } \\
\text { on the project? } \\
\text { - What attracted you to this project? } \\
\text { - Which projects did you conduct? Which decisions did } \\
\text { - Wou or do you regularly take? } \\
\text { What have you done with [name of the organization] that } \\
\text { you were unable to do elsewhere? }\end{array}$ \\
\hline $\begin{array}{l}\text { Interviewee's relation to forest } \\
\text { management("cognitive framing") }\end{array}$ & $\begin{array}{l}\text { - Do you see any links between forests and } \\
\text { climate change? } \\
\text { - What are the common objectives of forest } \\
\text { management for you? } \\
\text { - For forest experts and owners) } \\
\text { - Which professional or life path brought you } \\
\text { to work with/in the forest sector? } \\
\text { - How do you usually work in the forests that } \\
\text { you manage/own? }\end{array}$ & $\begin{array}{l}\text { - What are the forest operations that you usually do? } \\
\text { - } \quad \text { (forest experts) } \\
\text { - } \quad \text { How do you deal with the demands of the general } \\
\text { public/forestry sector? } \\
\text { - Which type of silviculture do you practice? (e.g., } \\
\text { mixed/monospecific stands, (ir)regular shelterwood) } \\
\text { - } \quad \text { (Forest owners) } \\
\text { - How did you choose your forest? } \\
\text { - Who did you choose to manage your forest? }\end{array}$ \\
\hline Project and its development & $\begin{array}{l}\text { - How did the idea of [name of the } \\
\text { organization] emerge? } \\
\text { - Did a founding moment occur? } \\
\text { - What were the building steps? }\end{array}$ & $\begin{array}{l}\text { - Have you noticed anything in the timber industry that } \\
\text { could be improved or that drove you toward this project? } \\
\text { - What was the identified need that gave rise to the project? } \\
\text { - What was the initial goal? Is it still the same? } \\
\text { - } \quad \text { Whor [name of the organization] staff members) } \\
\text { - } \quad \text { Based on which criteria did you choose them? } \\
\text { - How were the forestry experts chosen in the organization? } \\
\quad \text { How are the relationships between the different experts? }\end{array}$ \\
\hline
\end{tabular}


Table A3. Cont.

\begin{tabular}{|c|c|c|}
\hline Interview Category & Questions & Alternative Formulations to Relay the Question \\
\hline ResultsFunctioning & $\begin{array}{l}\text { - How do you monitor the results of the project? } \\
\text { - Have you fulfilled the initial objectives } \\
\text { can you men you joined the project? How } \\
\text { - Have you noticed any evolution regarding } \\
\text { the initial objectives or since you arrived? } \\
\text { - What does the regular progress of a project } \\
\text { look like? }\end{array}$ & $\begin{array}{l}\text { - What are the results? Are you satisfied? } \\
\text { - How did you respond to the identified need during the } \\
\text { - Caject design? } \\
\text { numbers talk about your impact assessment (tools, } \\
\text { - What is your strategy for contacting the different actors of } \\
\text { a new project? } \\
\text { - How did you raise funding? } \\
\text { - Could you describe a typical month for [name of } \\
\text { - } \quad \text { (Territorial anchorage): At which scale did you initially } \\
\text { design the project, and why? }\end{array}$ \\
\hline Sustainability & $\begin{array}{l}\text { - How do you monitor the reduction of your } \\
\text { carbon impact? } \\
\text { - How do you assess the biodiversity } \\
\text { dynamics (before and after the } \\
\text { implementation of the project)? }\end{array}$ & $\begin{array}{l}\text { - If your forests are already registered in a sustainable } \\
\text { management plan, what could be optimized in terms of } \\
\text { their carbon impact and biodiversity? } \\
\text { - Which method do you use to calculate your carbon } \\
\text { impact in forestry, and which factors do you include in } \\
\text { your method? } \\
\text { - Please describe your strategy to reduce your carbon } \\
\text { impact. How does it work? Does it focus on carbon } \\
\text { sequestration, storage, or substitution? } \\
\text { - On which environmental aspects do you focus the most, } \\
\text { and how do you chose your priorities? (Mention } \\
\text { biodiversity at this point if the interviewee has not yet } \\
\text { done so). }\end{array}$ \\
\hline $\begin{array}{l}\text { Project's capacity to help actors interact with } \\
\text { one another }\end{array}$ & $\begin{array}{l}\text { With whom do you work, and what does it } \\
\text { practically mean? To whom do you talk } \\
\text { about the carbon project? } \\
\text { - How often do you meet your counterparts? }\end{array}$ & $\begin{array}{l}\text { - (Personalize the questions depending on the interviewee's } \\
\text { connection with the carbon project): } \\
\text { - In your view, why is it important to work with the } \\
\text { forestry sector/corporations / public institutions? } \\
\text { - Do you think that [name of the organization] connects } \\
\text { different actors that rarely work together or interact? } \\
\text { - Do you think that you can help the timber industry in a } \\
\text { new way (e.g., hiring forest workers)? }\end{array}$ \\
\hline Potential evolution of the project & $\begin{array}{l}\text { - Do you have plans for future developments? } \\
\text { - Do you know about any similar initiatives } \\
\text { with the same objectives? } \\
\text { - How are you evolving in the national } \\
\text { context of multiple climate policies? }\end{array}$ & $\begin{array}{l}\text { - How do you see the project evolving in the coming years? } \\
\text { - What are your objectives for the years to come? } \\
\text { - } \text { which ones and why? } \\
\text { - Do you think that your project is more suitable for a } \\
\text { particular type of territory, or can it be used everywhere? } \\
\text { Can it be applied to ecosystems other than forests? } \\
\text { - Did you contribute to the national adaptation plan, } \\
\text { mitigation strategy, etc.? }\end{array}$ \\
\hline
\end{tabular}

\section{Appendix C}

Analysis grid for the transcribed interviews.

Appendix C.1 Objectives/Issues of the Organizations ("Why"?)

Appendix C.1.1 Issues Specific to Only One Organization/Code \#1

- $\quad$ Normandie Forêver (NF): forest dieback (for foresters and beneficiaries)

- Sylv'ACCTES: sustainable management of forests, wood production, relationship with the public

Appendix C.1.2 Issues Common to Both Organizations/Code \#2

- Content of the offset contracts (biodiversity or social development clauses)

- Managing private forests areas (gathering together private owners, leading them toward a more efficient and sustainable forest management)

- Need for fuelwood energy supply

Appendix C.2 Organizational Processes ("How"?)

Appendix C.2.1 Organizational Processes Specific to Only One Organization/Code \#3

- Funding methods

Appendix C.2.2 Organizational Processes Common to Both Organizations/Code \#4

- Distribution of decisional power between stakeholders 
- Actors involved (private-public partnership)

- Jurisdictional form as nonprofit organizations

- Spatial and temporal scale > local development

Appendix C.2.3 Results Obtained/Code \#5

- Quantitative results $>$ area covered, money collected, future perspectives

Appendix C.3 Carbon Mitigation in the Organization's Development

Appendix C.3.1 Cognitive Framing of the Process/Code \#6

- $\quad \mathrm{NF}>$ main goal is carbon mitigation, with firms paying for the restoration of the forest dieback and thus contributing to carbon mitigation

- $\quad$ SACC > carbon mitigation is one of the positive externalities of sustainable forest management, BUT it is an appealing argument to carbon offsetters

Appendix C.3.2 Calculation of Carbon Storage/Code \#7

- Methodology used

- Control of results obtained

\section{References}

1. Seidl, R.; Thom, D.; Kautz, M.; Martin-Benito, D.; Peltoniemi, M.; Vacchiano, G.; Wild, J.; Ascoli, D.; Petr, M.; Honkaniemi, J.; et al. Forest Disturbances under Climate Change. Nat. Clim. Chang. 2017, 7, 395-402. [CrossRef]

2. Keenan, R.J. Climate Change Impacts and Adaptation in Forest Management: A Review. Ann. For. Sci. 2015, 72, 145-167. [CrossRef]

3. Huang, L.; Zhou, M.; Lv, J.; Chen, K. Trends in global research in forest carbon sequestration: A bibliometric analysis. J. Clean. Prod. 2020, 252, 119908. [CrossRef]

4. Mayer, M.; Prescott, C.E.; Abaker, W.E.A.; Augusto, L.; Cécillon, L.; Ferreira, G.W.D.; James, J.; Jandl, R.; Katzensteiner, K.; Laclau, J.-P.; et al. Tamm review: Influence of forest management activities on soil organic carbon stocks: A knowledge synthesis. For. Ecol. Manag. 2020, 466, 118127. [CrossRef]

5. Fouqueray, T.; Frascaria-Lacoste, N. Social sciences have so much more to bring to climate studies in forest research: A French case study. Ann. For. Sci. 2020, 77, 81. [CrossRef]

6. Corbera, E. Problematizing REDD+ as an experiment in payments for ecosystem services. Curr. Opin. Environ. Sustain. 2012, 8, 612-619. [CrossRef]

7. Blanc, S.; Accastello, C.; Bianchi, E.; Lingua, F.; Vacchiano, G.; Mosso, A.; Brun, F. An integrated approach to assess carbon credit from improved forest management. J. Sustain. For. 2019, 38, 31-45. [CrossRef]

8. Duncker, P.S.; Raulund-Rasmussen, K.; Gundersen, P.; Katzensteiner, K.; De Jong, J.; Ravn, H.P.; Smith, M.; Eckmüllner, O.; Spiecker, H. How forest management affects ecosystem services, including timber production and economic return: Synergies and trade-offs. Ecol. Soc. 2012, 17. [CrossRef]

9. Fouqueray, T.; Charpentier, A.; Trommetter, M.; Frascaria-Lacoste, N. The calm before the storm: How climate change drives forestry evolutions. For. Ecol. Manag. 2020, 460, 117880. [CrossRef]

10. Borrass, L.; Kleinschmit, D.; Winkel, G. The "German model” of integrative multifunctional forest management-Analysing the emergence and political evolution of a forest management concept. For. Policy Econ. 2017, 77, 16-23. [CrossRef]

11. Cubbage, F.; Harou, P.; Sills, E. Policy instruments to enhance multi-functional forest management. For. Policy Econ. 2007, 9, 833-851. [CrossRef]

12. Hommel, T.; Godard, O. Que peut-on espérer des entreprises socialement responsables? In Regards Sur la Terre 2009; Annuels; Presses de Sciences Po: Paris, France, 2009; pp. 167-178. ISBN 978-2-7246-1091-8.

13. Hamrick, K.; Gallant, M. Voluntary Carbon Markets Insights: 2018 Outlook and First-Quarter Trends; Ecosystem Marketplace, Forest Trends: Washington, DC, USA, 2018.

14. Bertolas, R.J. Cross-Cultural environmental perception of wilderness. Prof. Geogr. 1998, 50, 98-111. [CrossRef]

15. Cooley, D.M.; Galik, C.S.; Holmes, T.P.; Kousky, C.; Cooke, R.M. Managing dependencies in forest offset projects: Toward a more complete evaluation of reversal risk. Mitig. Adapt. Strateg. Glob. Chang. 2012, 17, 17-24. [CrossRef]

16. Phelps, J.; Webb, E.L.; Agrawal, A. Does REDD+ threaten to recentralize forest governance? Science 2010, 328, 312-313. [CrossRef] [PubMed]

17. MAAF. Programme National de La Forêt et Du Bois 2016-2026; Ministère de l'Agriculture, de l'Agroalimentaire et de la Forêt: Paris, France, 2017; p. 60.

18. Barthod, C. La Multifonctionnalité des forêts entre discours et pratiques: Illusion ou réalité à assumer? Rev. For. Française 2015, 4, 293-319. [CrossRef] 
19. Boy, D. Le grenelle de l'environnement: Une novation politique? Rev. Française Adm. Publique 2010, 134, 313-324. [CrossRef]

20. Legifrance. Légifrance Décret $N^{\circ}$ 2012-557 Du 24 Avril 2012 Relatif Aux Obligations de Transparence Des Entreprises En Matière Sociale et Environnementale; Legifrance: Paris, France, 2012.

21. Tronquet, C.; Grimault, J.; Foucherot, C. Etudes Climat. January 2017, p. 32. Available online: https://www.i4ce.org/wp-core/ wp-content/uploads/2017/01/Potentiel-et-d\%C3\%A9terminants-de-la-demande-volontaire-en-cr\%C3\%A9dits-carbone-enFrance-9.pdf (accessed on 5 November 2018).

22. CNPF Forêt et Carbone. Available online: https://www.cnpf.fr/n/foret-et-carbone (accessed on 4 September 2020).

23. Gren, I.-M.; Aklilu, A.Z. Policy design for forest carbon sequestration: A review of the literature. For. Policy Econ. 2016, 70, 128-136. [CrossRef]

24. UNFCCC. Kyoto Protocol-Reference Manual on Accounting of Emissions and Assigned Amount; UNFCCC: Bonn, Germany, 2007.

25. IPCC Change. Climate Change 2014: Mitigation of Climate Change; Edenhofer, O.R., Pichs-Madruga, Y., Sokona, E., Farahani, S., Kadner, K., Seyboth, A., Adler, I., Baum, S., Brunner, P., IPCC, Eds.; Working Group III Contribution to the Fifth Assessment Report of the Intergovernmental Panel on Climate Change; Cambridge University Press: Cambridge, UK; New York, NY, USA, 2014; ISBN 978-1-107-05821-7.

26. Pretzsch, H.; Forrester, D.I.; Rötzer, T. Representation of species mixing in forest growth models. A review and perspective. Ecol. Model. 2015, 313, 276-292. [CrossRef]

27. Biber, P.; Borges, J.; Moshammer, R.; Barreiro, S.; Botequim, B.; Brodrechtová, Y.; Brukas, V.; Chirici, G.; Cordero-Debets, R.; Corrigan, E.; et al. How sensitive are ecosystem services in European forest landscapes to silvi-cultural treatment? Forests 2015, 6, 1666-1695. [CrossRef]

28. Brockerhoff, E.G.; Barbaro, L.; Castagneyrol, B.; Forrester, D.I.; Gardiner, B.; González-Olabarria, J.R.; Lyver, P.O.; Meurisse, N.; Oxbrough, A.; Taki, H.; et al. Forest biodiversity, ecosystem functioning and the provision of eco-system services. Biodivers. Conserv. 2017, 26, 3005-3035. [CrossRef]

29. Mathias, J.-D.; Bonté, B.; Cordonnier, T.; de Morogues, F. Using the viability theory to assess the flexibility of forest managers under ecological intensification. Environ. Manag. 2015, 56, 1170-1183. [CrossRef]

30. Barnaud, C.; Corbera, E.; Muradian, R.; Salliou, N.; Sirami, C.; Vialatte, A.; Choisis, J.-P.; Dendoncker, N.; Mathevet, R.; Moreau, C. Ecosystem services, social interdependencies, and collective action: A conceptual framework. Ecol. Soc. 2018, 23. [CrossRef]

31. IFN Inventaire Forestier National. Available online: http:/ /inventaire-forestier.ign.fr/ (accessed on 27 January 2020).

32. Cashore, B.; Egan, E.; Auld, G.; Newsom, D. Revising theories of nonstate market-driven (NSMD) governance: Lessons from the finnish forest certification experience. Glob. Environ. Politics 2007, 7, 1-44. [CrossRef]

33. Sylv'ACCTES. Available online: http://www.sylvacctes.org/ (accessed on 10 July 2019).

34. Gusti, M.; Di Fulvio, F.; Biber, P.; Korosuo, A.; Forsell, N. The effect of alternative forest management models on the forest harvest and emissions as compared to the forest reference level. Forests 2020, 11, 794. [CrossRef]

35. Luyssaert, S.; Schulze, E.-D.; Börner, A.; Knohl, A.; Hessenmöller, D.; Law, B.E.; Ciais, P.; Grace, J. Old-Growth forests as global carbon sinks. Nature 2008, 455, 213-215. [CrossRef] [PubMed]

36. Stephenson, N.L.; Das, A.J.; Condit, R.; Russo, S.E.; Baker, P.J.; Beckman, N.G.; Coomes, D.A.; Lines, E.R.; Morris, W.K.; Rüger, N.; et al. Rate of tree carbon accumulation increases continuously with tree size. Nature 2014, 507, 90-93. [CrossRef]

37. Jonard, M.; Nicolas, M.; Coomes, D.A.; Caignet, I.; Saenger, A.; Ponette, Q. Forest soils in France are sequestering substantial amounts of carbon. Sci. Total Environ. 2017, 574, 616-628. [CrossRef]

38. Shin, S.; Yeo-Chang, Y. Perspectives of private forest owners toward investment in forest carbon offset projects: A case of Geumsan-Gun, South Korea. Forests 2019, 10, 21. [CrossRef]

39. Maraseni, T.N.; Dargusch, P. Expanding woodland regeneration on marginal southern queensland pastures using market-based instruments: A landowners' perspective. Australas. J. Environ. Manag. 2008, 15, 104-112. [CrossRef]

40. Fortmann, L.; Cordero, P.; Sohngen, B.; Roe, B. Incentive Contracts for Environmental Services and Their Potential in REDD.; The World Bank: Washington, DC, USA, 2014.

41. ONF. Contrat d'objectifs et de Performance 2016-2020; Office national des forêts: Paris, France, 2016.

42. Cinotti, B. Une gestion non rentable peut-elle être durable? Rev. For. Française 2003, 55, 7-24. [CrossRef]

43. Barthod, C. La Réforme des financements publics aux investissements forestiers. Rev. For. Française 2001, 9. [CrossRef]

44. Legifrance. Légifrance Code Général Des Impôts-Article 238 Bis; Legifrance: Paris, France, 2018.

45. Primmer, E.; Paloniemi, R.; Similä, J.; Tainio, A. Forest owner perceptions of institutions and voluntary contracting for biodiversity conservation: Not crowding out but staying out. Ecol. Econ. 2014, 103, 1-10. [CrossRef]

46. CNPF. CNPF-Centre National de La Propriété Forestière. Available online: https://www.cnpf.fr/ (accessed on 24 June 2019).

47. Baskent, E.Z.; Borges, J.G.; Kašpar, J.; Tahri, M. A design for addressing multiple ecosystem services in forest management planning. Forests 2020, 11, 1108. [CrossRef]

48. Gutierrez Garzon, A.R.; Bettinger, P.; Siry, J.; Abrams, J.; Cieszewski, C.; Boston, K.; Mei, B.; Zengin, H.; Yeşil, A. A comparative analysis of five forest certification programs. Forests 2020, 11, 863. [CrossRef]

49. Bernstein, S.; Cashore, B. Can non-state global governance be legitimate? An analytical framework. Regul. Gov. $2007,1,347-371$. [CrossRef]

50. Perrin, M.; de Noblet-Ducoudré, N.; Strada, S.; Torre, A. Plaidoyer pour le développement d'une action clima-tique régionale: Aménagement de l'espace, usage des sols et conditions atmosphériques. Norois Environ. Amenage. Soc. 2017, 29-45. [CrossRef] 
51. Ostrom, E. Beyond markets and states: Polycentric governance of complex economic systems. Am. Econ. Rev. 2010, 100, 641-672. [CrossRef]

52. Benz, J.P.; Chen, S.; Dang, S.; Dieter, M.; Labelle, E.R.; Liu, G.; Hou, L.; Mosandl, R.M.; Pretzsch, H.; Pukall, K.; et al. Multifunctionality of forests: A white paper on challenges and opportunities in China and Germany. Forests 2020, 11, 266. [CrossRef]

53. Konadu, D.D.; Mourão, Z.S.; Allwood, J.M.; Richards, K.S.; Kopec, G.; McMahon, R.; Fenner, R. Land use implications of future energy system trajectories-The case of the UK 2050 carbon plan. Energy Policy 2015, 86, 328-337. [CrossRef]

54. Legifrance. Légifrance Décret No 2018-1043 Du 28 Novembre 2018 Créant Un Label "Bas-Carbone"; Legifrance: Paris, France, 2018.

55. Barthod, C. Qu'a apporté le débat sur la gestion durable à la foresterie française? Ce débat doit-il être dépassé? Rev. For. Française 2007, 59. [CrossRef]

56. Assuah, A.; Sinclair, A.J. Unraveling the relationship between collective action and social learning: Evidence from community forest management in Canada. Forests 2019, 10, 494. [CrossRef]

57. UICN France. Les Solutions Fondées Sur La Nature Pour Lutter Contre Les Changements Climatiques et Réduire Les Risques Naturels En France; IUCN: Paris, France, 2018. 